\title{
AUNANDO COLABORACIÓN CON UNA GESTIÓN MÁS EFICAZ Comentario del artículo de Heckscher y Martín-Ríos
}

\author{
LINKING COLLABORATION WITH IMPROVED ADMINISTRATION \\ A commentary on Heckscher and Martín-Ríos article ${ }^{2}$
}

\author{
NICLAS ERHARDT niclas.erhard@@Maine.edu \\ Maine Business School. University of Maine. EEUU. \\ Ivan Manev imanev@Maine.edu \\ Maine Business School. University of Maine. EEUU.
}

Actualmente, existen pocas dudas sobre la necesidad acuciante de transformación a la que se enfrenta el actual modelo organizativo universitario, tal y como apuntan los profesores Heckscher y Martín-Ríos. El argumento principal de su artículo apunta a que el modelo gremial sobre el que se funda ha prescrito. La respuesta más común en estos tiempos es virar hacia un modelo administrativo-burocrático que mejore la eficiencia y capacidad de control del sistema. En este sentido, la aportación de los autores al debate actual es importante, sobre todo en lo que respecta a arrojar luz sobre la paradoja en la que se construye esta solución: las universidades caminan hacia un modelo clásico jerárquico-burocrático de gestión en el momento actual en el cada vez son más las corporaciones que han descubierto sus limitaciones y buscan alternativas en los modelos colaborativos basados en equipos multidisciplinares. La tesis de Heckscher y Martín-Ríos es que las universidades deberían superar los modelos gremiales de las profesiones artesanales y afrontar los retos de un modelo colaborativo alrededor de múltiples stakeholders en el que los proveedores de servicios (académicos) y los receptores (estudiantes, empresas, instituciones públicas y la sociedad en general) trabajen juntos para diseñar y ofertar una agenda educativa unificada.

Compartimos el argumento propuesto por los autores de que introducir modelos colaborativos en la organización universitaria es vital para su sostenibilidad y desarrollo, si bien queremos extenderlo aquí y proponer que no se trata de plantear una solución excluyente entre alternativas organizativas, sino más bien una mejor combinación de ambos modelos -el colaborativo y el control administrativo, el que mejor puede contribuir a la tan necesaria transformación en la gestión universitaria. Las universidades deben mejorar su eficacia y eficiencia para responder a los retos que se avecinan: unas

\footnotetext{
${ }^{2}$ En la versión online de este artículo se puede encontrar material adicional en: http://papers.ssrn.com/sol3/papers.cfm?abstract_id=2391409
} 
tasas de natalidad decrecientes (al menos en la mayoría de países industrializados), un apoyo institucional decreciente (tanto en provisión de fondos públicos para la gestión universitaria como en inversión en investigación básica), junto a una competencia por recursos y estudiantes mayor y más globalizada que nunca.

Algunas empresas de éxito han transitado hacia modelos colaborativos, pero lo han hecho manteniendo un control rígido sobre la gestión de resultados, tal y como el modelo administrativo preconiza. La implantación por parte de las universidades de un modelo que aúne gestión colaborativa y control de la responsabilidad y los resultados, puede contribuir a que evitar el colapso definitivo. Siendo totalmente honestos, estas propuestas suponen necesariamente unos mayores niveles de exigencia para nosotros los académicos. Al requisito de mejorar los niveles individuales de especialización en una determinada área de conocimiento habría que añadir el de la trabajar efectivamente de forma multidisciplinar y colaborativa con diversos agentes: otros académicos, estudiantes, potenciales empleadores de los egresados, instituciones interesadas en la transferencia de conocimiento, etc.

Ciertamente las universidades pueden beneficiarse de la experiencia acumulada por algunas empresas en sus procesos de transformación organizativa. El mismo razonamiento se aplica igualmente en el caso contrario. El objetivo último de la actividad académica es 'la búsqueda del conocimiento'-en nuestro caso concreto es la observación, análisis y síntesis de la realidad compleja en el ámbito de la gestión y organización de empresas para facilitar su comprensión. Para ello, contamos con un sistema organizativo que nos permite afrontar la tarea sin interferencias. Y ello es posible gracias al sistema de titularidad académica, un componente diferenciador que convierte al mundo académico universitario en único. Aun cuando el debate sobre la viabilidad del sistema vitalicio va más allá del objetivo de este ensayo (si bien es necesario reconocer que ha recibido críticas incluso por parte de los propios académicos), en pocas palabras, el propósito fundamental del sistema de cátedra es el de proteger la libertad académica de posibles intromisiones interesadas. Esta libertad también significa que los académicos son libres de colaborar con colegas en otras áreas del saber, universidades y países.

Ahora bien, la libertad académica que tan atractiva les resulta a los académicos puede a la larga suponer una fuente de problemas cuando el esfuerzo de profesorado se aleja de las necesidades de los estudiantes, inquietos por su futuro laboral. Tal y como nos plantean Heckscher y Martín-Ríos, sirvan de ejemplo los estudiantes de postgrado en las escuelas de negocio donde sus responsables necesitan que los programas educativos garanticen unos niveles de aprendizaje satisfactorios en una variedad de áreas, al tiempo que unos resultados óptimos en términos de resultados -capacidad de emprender 0 emplearse de sus egresados. Aquí es donde la libertad académica y las necesidades curriculares pueden entrar en conflicto y donde, en nuestra opinión, un nivel óptimo de burocracia y control pueden resultar de utilidad. Por un lado, los académicos normalmente tienen libertad de cátedra para desarrollar sus propios programas educativos. Por otro lado, la administración universitaria, en correspondencia con las diversas entidades acreditadoras, ejercen control para programar los cursos, horarios, 
y responder a las demandas de matriculación. En última instancia, los administradores universitarios intentan que los profesores se adecuen a los objetivos de aprendizaje preestablecidos, los cuales son en gran medida delineados por la dirección de la escuela de negocios. Sin instrumentos de supervisión, la adecuación curricular quedaría exclusivamente en manos de los docentes, sin posibilidad alguna de control por parte de los directores académicos y gerentes universitarios.

Por tanto, un modelo que aúne colaboración y control administrativo resulta ineludible. Sólo de esta forma es posible atender las necesidades del resto de grupos de interés; por ejemplo los potenciales empleadores de estudiantes. Pongamos por caso la situación de los jóvenes egresados en Suecia (por otro lado, paradigma de mercado de trabajo sostenible), los cuales se enfrentan a unos niveles de desempleo superiores a los de los buscadores de empleo con mayor edad. La tasa de desempleo entre los jóvenes menores de 25 años es cercana al 24 por ciento, tres veces superior a la media nacional. Sin embargo, los resultados de investigaciones llevadas a cabo por Erik Lindqvist y Roine Westman ponen de manifiesto la existencia de bolsas de trabajo para los jóvenes sin aprovechar. La paradoja se explica en el hecho de que los jóvenes a menudo carecen de las competencias no cognitivas necesarias para acceder al empleo, tales como disciplina, habilidades sociales, motivación, persistencia, puntualidad, o estabilidad emocional.

El argumento es que, en parte debido a la falta de comunicación entre los diversos grupos implicados, las universidades y los académicos perpetúan el desinterés hacia estas "habilidades blandas" y se enfocan casi exclusivamente en habilidades cognitivas "duras". Un modelo de gestión burocrático centrado en indicadores de desempeño objetivos sólo contribuye a acentuar estos desajustes. La calidad docente difícilmente puede ser evaluada por criterios tan poco objetivos como el aprendizaje de habilidades sociales.

¿Cuál es la solución más apropiada? Coincidimos con Heckscher y Martín-Ríos en la necesidad de afrontar un modelo abierto de universidad. Éstas necesitan promover el desarrollo de lazos entre disciplinas y grupos académicos, entre universidades, así como fuera del ámbito universitario. Después de todo, en lo que respecta a los alumnos, es nuestra responsabilidad que una vez finalizado su periodo de aprendizaje, éstos sean buenos ciudadanos con buenas opciones de aplicar el conocimiento adquirido a través de un empleo. Las buenas noticias son que los estudiantes pueden adquirir todas las habilidades requeridas, tal y como propone el premio Nobel James Heckman, a través de la interacción con empleadores locales, obteniendo experiencia laboral con contratos en prácticas, voluntariado, o la participación en proyectos donde los estudiantes se percaten de la importancia de la puntualidad, la capacidad de sacrificio o la ética profesional. Sin embargo, para que esto ocurra es necesaria no sólo una mayor colaboración con las empresas e instituciones sino también una mayor intervención administrativa que garantice el compromiso por parte de los académicos.

En algunas universidades se están dando pasos en la dirección propuesta con el fin de promover relaciones colaborativas con agentes externos. Una de ellas se plasma 
en el Proyecto Login (www.projectlogin.com), un acuerdo entre la universidad de Maine y empresas de todo el estado de Maine interesadas en formar a sus profesionales en aspectos relacionados con las telecomunicaciones. Otro ejemplo lo constituye la Knowledge Transfer Alliance (www.umaine.edu/kta), un proyecto colaborativo entre varios departamentos (la Escuela de Económicas, la Escuela de Negocios, la facultad de Ingeniería y el departamento de Extensión), que ofrece asesoramiento especializado a empresas. Finalmente, la Maine Humanities Initiative (www.umaine.edu/umhi) es una iniciativa reciente en el área de las humanidades que pretende promover el interés por temas relacionados con la cultura, la creatividad y la reflexión crítica a través de la creación de vínculos interdisciplinares con diversas instituciones.

Hay varias características comunes a estos procesos de colaboración. Primero, mientras todos ellos avanzan la misión de la universidad en sus tres áreas básicas -docencia, investigación y servicio- plantean un interés específico hacia los actores externos. Además, parten de la estructura organizativa existente, en lugar de substituirla. También son flexibles y dependen para su buen funcionamiento de las fuentes externas de financiación. En cuarto lugar, son multidisciplinares e involucran tanto a empresas e instituciones como a diversas áreas académicas. Y, finalmente, se añaden a las actividades habituales de los departamentos y profesorados, para lo cual se requiere mayor coordinación, iniciativa y responsabilidad.

En definitiva, el artículo de Heckscher y Martín-Ríos es provocador, al tiempo que oportuno en su publicación. Más si cabe, en estos momentos en los que se hace urgente presentar propuestas de cambio organizativo para unas universidades públicas acuciadas por la escalada en los costes de funcionamiento y la intensificación de una competencia global y local por atraer estudiantes. Es, sin duda, un tema complejo donde todos los grupos de interés involucrados reconocen la necesidad de cambio. Nuestro comentario pretende añadir puntos de vista complementarios al de los autores sobre cómo diseñar estrategias de cambio que faciliten la adaptación de las universidades a las nuevas demandas.

Niclas ERHARdt (Ph.D., Rutgers University) es assistant professor en la Maine Business School de la Universidad de Maine, USA. Sus intereses de investigación incluyen el trabajo en equipo en entornos intensivos en conocimiento, las dinámicas grupales y el aprendizaje colaborativo, la dirección estratégica de recursos humanos y la gestión de la diversidad en el ámbito laboral.

Ivan Manev (Ph.D., Boston College) ocupa el cargo de Decano de la Maine Business School en la Universidad de Maine, USA. Catedrático de organización de empresas ocupa la cátedra Nicolas M. Salgo de Administración de Empresas. Ha escrito numerosos trabajos en el area de creación de empresas en economías emergentes, liderazgo multicultural y teoría de redes sociales. 